OPEN ACCESS

Edited by:

Paul Bodelier,

Netherlands Institute of Ecology (NIOO-KNAW), Netherlands

Reviewed by:

Nathan Basiliko,

Laurentian University, Canada Roey Angel,

University of Vienna, Austria Sarah Elizabeth Evans, Kellogg Biological Station Michigan

State University, USA

*Correspondence:

Don A. Cowan,

Centre for Microbial Ecology and Genomics, University of Pretoria, Natural Sciences Building II, Hatfield 00028, South Africa

don.cowan@up.ac.za

Specialty section: This article was submitted to Terrestrial Microbiology, a section of the journal Frontiers in Microbiology

Received: 29 April 2015 Accepted: 03 August 2015 Published: 04 September 2015

Citation:

Ronca S, Ramond J-B, Jones $B E$, Seely M and Cowan DA (2015) Namib

Desert dune/interdune transects exhibit habitat-specific edaphic bacterial communities.

Front. Microbiol. 6:845 doi: 10.3389/fmicb.2015.00845

\section{Namib Desert dune/interdune transects exhibit habitat-specific edaphic bacterial communities}

\author{
Sandra Ronca ${ }^{1}$, Jean-Baptiste Ramond ${ }^{1}$, Brian E. Jones ${ }^{1,2}$, Mary Seely ${ }^{3,4}$ and \\ Don A. Cowan ${ }^{1 *}$
}

'Department of Genetics, Centre for Microbial Ecology and Genomics, University of Pretoria, Pretoria, South Africa, ${ }^{2}$ DuPont Industrial Biosciences, Leiden, Netherlands, ${ }^{3}$ Gobabeb Research and Training Centre, Walvis Bay, Namibia, ${ }^{4}$ School of

Animal, Plant and Environmental Sciences, University of the Witwatersrand, Johannesburg, South Africa

The sand dunes and inter-dune zones of the hyper-arid central Namib Desert represent heterogeneous soil habitats. As little is known about their indigenous edaphic bacterial communities, we aimed to evaluate their diversity and factors of assembly and hypothesized that soil physicochemistry gradients would strongly shape dune/interdune communities. We sampled a total of 125 samples from 5 parallel dune/interdune transects and characterized 21 physico-chemical edaphic parameters coupled with $16 \mathrm{~S}$ rRNA gene bacterial community fingerprinting using T-RFLP and 454 pyrosequencing. Multivariate analyses of T-RFLP data showed significantly different bacterial communities, related to physico-chemical gradients, in four distinct dune habitats: the dune top, slope, base and interdune zones. Pyrosequencing of $16 \mathrm{~S}$ rRNA gene amplicon sets showed that each dune zone presented a unique phylogenetic profile, suggesting a high degree of environmental selection. The combined results strongly infer that habitat filtering is an important factor shaping Namib Desert dune bacterial communities, with habitat stability, soil texture and mineral and nutrient contents being the main environmental drivers of bacterial community structures.

Keywords: deterministic assembly, open soil, habitat filtration, dune transects, environmental gradient, arid ecosystems

\section{Introduction}

Despite extreme surface conditions, notably (hyper-) aridity, wide daily temperature fluctuations, high UV radiation and oligotrophy, edaphic microbial communities have been shown to flourish in desert soils (Makhalanyane et al., 2015). The Namib Desert of south-western Africa is considered to be one of the oldest desert regions on Earth (Eckardt and Spiro, 1999). It is characterized by a wide range of different soil environments including gravel plains, sand dunes, inselbergs, escarpments, river beds, salt pans and playas (Seely, 2012; Eckardt et al., 2013a). In the central Namib Desert, studies have notably determined that local soil physicochemical conditions and climate played a significant role in the assembly of edaphic and hypolithic communities were (e.g., Stomeo et al., 2013; Warren-Rhodes et al., 2013; Ramond et al., 2014; Gombeer et al., 2015).

However, and despite representing over $41 \%$ of the total desert land surface (Seely, 2012), the detailed microbial ecology (as determined by modern molecular tools) of the Namib Sand Sea has to date poorly been assessed and essentially focused on fungal communities (Jacobson, 1997; Jacobson and Jacobson, 1998; Jacobson et al., 2015). The dispersal and colonization of mycorrhizal 
fungal communities were shown to depend on sand stability and moisture availability, respectively (Jacobson, 1997). And, moisture-activated decomposing fungi were observed on the litter of the perennial Namib dune grass Stipagrostis sabulicola and in dune sands (Jacobson and Jacobson, 1998; Jacobson et al., 2015). Recently, a T-RFLP fingerprinting-based study compared the edaphic bacterial community assemblages from multiple soil surface geologies and lithologies of the central Namib Desert. It showed that (i) interdune bacterial communities were significantly different than those of the gravel plains and riverbeds and that (ii) the soil physicochemistry and lithology of the different interdunes sampled were important in structuring their indigenous communities (Gombeer et al., 2015).

Dune morphology and dynamics have in contrast extensively been studied in the Namib Desert. Three geographically distinct dune morphology patterns have been characterized: transverse dunes to the west (i.e., toward the coast), linear and complex linear dunes in the center and star dunes in the east (i.e., inland) (Livingstone, 2013). Similarly, an east/west sand color gradient, from yellowish brown (west) to much redder (east), has been described and attributed to variations in iron oxide and clay mineral concentrations (Walden and White, 1997; Livingstone, 2013). Within dune slopes, a complex moisture gradient has been shown to influence the number of species perennial grasses as well as their growth strategies and distribution (Yeaton, 1988; Seely, 1990). Dunes have also been described to be highly dynamic environments, as they are constantly modified by surface shear forces and mechanical stresses. For example, it has been reported annual transverse dune crest migrations varying from 4 to $56 \mathrm{~m}$ (Livingstone, 2013). Wind has also been shown to alter the top of wind-exposed slopes (or stoss slopes) and sand accumulation to dominate along lee slopes (or downwind slopes) (Lancaster, 1985; Eckardt et al., 2013a). The interactions between wind erosion and sediment deposition lead to discernible patterns in grain size and sorting gradients both on individual dune slopes and between dune and interdune areas.

In such a dynamic and heterogeneous habitat, dune microbial communities have thus to cope with numerous stresses, including environmental physical instability, fluctuating soil physicochemical properties, low water availability, high temperatures, oligotrophy and alkaline $\mathrm{pH}$ (typically around 8) (Makhalanyane et al., 2015); all of which have been shown to affect both community diversity and function (Andrew et al., 2012; Kuske et al., 2012; Yu and Steinberger, 2012a; Makhalanyane et al., 2015).

Using the Kahani dune system in the Namib Sand Sea as a model dune environment, we aimed to determine drivers shaping edaphic bacterial community diversity in four dune biotopes (dune top, slope, base, and interdune). We hypothesized that in such a dynamic environment, strong soil physicochemical gradients would structure bacterial communities; i.e., that deterministic processes would lead to dune habitat-specific communities. Our related null hypothesis stated that high dispersal rates, due to the important dynamicity of dune ecosystems, would lead to homogenized communities (Leibold and Norberg, 2004). To test these hypotheses, we collected 125 soil samples from 5 parallel dune/interdune transects in a single Namib Desert dune system; i.e., from the summit of a western dune to the crest of an eastern dune. For each sample, we recorded 21 edaphic physico-chemical parameters and characterized the bacterial community structure by $16 \mathrm{~S}$ rRNA gene T-RFLP analyses. We also performed $16 \mathrm{~S}$ rRNA gene pyrosequencing on representative samples of 7 putative dune habitats found across the dune/interdune transect, namely the east and west dune tops, slopes bases and the interdune, to investigate their taxonomic composition and assess if they presented different assemblages.

\section{Materials and Methods}

\section{Study Site and Soil Sample Collection}

Soil samples were collected in April 2013 in the Kahani dune system (S $23^{\circ} 35.830^{\prime} / \mathrm{E} 15^{\circ} 01.800^{\prime}$ ), a typical complex linear dune in the Namib Desert Sand Sea (Figure 1). 25 soil samples were collected from each of five parallel (40 m apart) $2 \mathrm{~km}$ long dune/interdune linear transects from the west (stoss slope) to the opposite east dune (lee slope) resulting in a total of 125 soil samples (Figure 1). Each transect was divided into 4 morphologically distinct zones: dune Top, Slope, Base and Interdune. Sampling points were regularly distributed; every $40 \mathrm{~m}$ from the west dune Top to its base, every $200 \mathrm{~m}$ in the Interdune area and every $20 \mathrm{~m}$ on the eastern dune up to the dune Top, as the west facing dune was typically shorter and steeper than the east facing dune (Figure 1). Surface soil samples (0$5 \mathrm{~cm}$ depth) were collected (avoiding grasses on the dune Slope to minimize any rhizosphere bias), and each individual sample comprised the pooling of four pseudo-replicate soils in a $1 \mathrm{~m}^{2}$ area. Samples were stored at $4^{\circ} \mathrm{C}$ for soil chemistry analysis, at $-20^{\circ} \mathrm{C}$ for molecular analysis and processed immediately for fluorescein di-acetate (FDA) assays.

\section{Soil Physico-chemistry Analyses}

All analyses were performed at the Soil Science Laboratory of the University of Pretoria. Prior to analyses of 21 edaphic parameters, the soil samples were sieved ( $2 \mathrm{~mm}$ mesh) and dried overnight at $37^{\circ} \mathrm{C}$. $\mathrm{pH}$ was measured in $10 \mathrm{~g}$ soil slurries (1:2.5 soil/deionized water) with a $\mathrm{pH}$ meter (Crison basic 20, Barcelona, Spain) (Eckert and Sims, 1995). Soil nitrate $\left(\mathrm{NO}_{3}^{-}-\mathrm{N}\right)$ and ammonium $\left(\mathrm{NH}_{4}^{+}-\mathrm{N}\right)$ were determined by extraction $(2 \mathrm{M} \mathrm{KCl})$ and steam distillation with subsequent titration performed as described by Keeney and Nelson (1982). Soil total carbon percentage (C) was measured by oxidizing the organic material with chromic acid and titrating the excess dichromate (Walkley, 1935; Nelson, 1982). Cation exchange capacity (CEC) was determined using an ammonium acetate solution as extractant for the exchangeable and water-soluble cations with steam distillation to separate the ammonia (Rhoades, 1982). Ammonium acetate extraction was also used to measure salt concentrations $(\mathrm{Na}, \mathrm{K}, \mathrm{Mg}$, and $\mathrm{Ca}$ ) using inductively coupled plasma atomic emission spectroscopy (ICP-OES) (Spectro Genesis, Spectro Analytical Instruments GmbH, Germany). The Bray-1 method (Bray and Kurtz, 1945) was used to quantify extractable phosphorous (P). Metals (Fe, $\mathrm{Al}$, and $\mathrm{Mn}$ ) were extracted from $10 \mathrm{~g}$ of soil using EDTA buffer and quantified by ICP-OES after filtration through a 


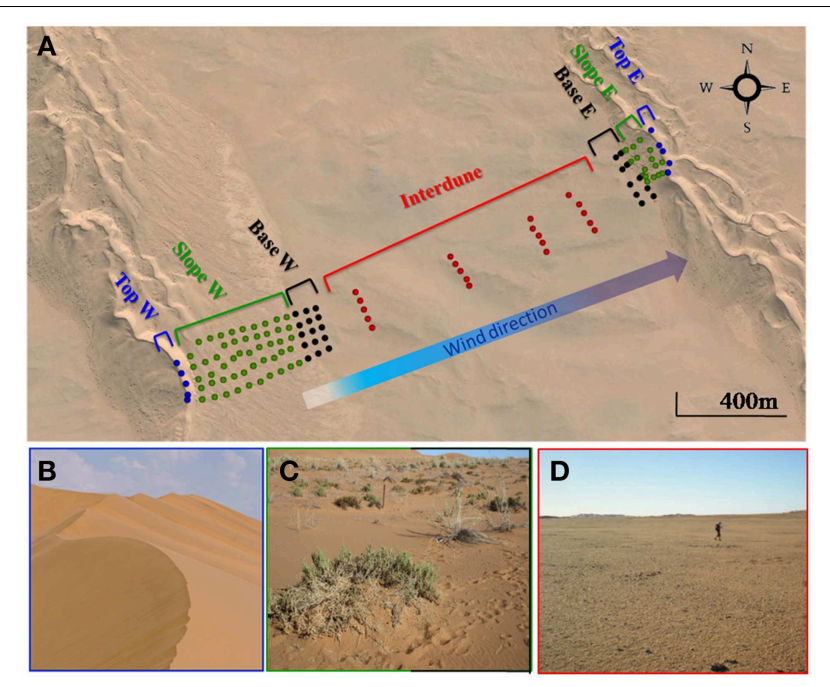

FIGURE 1 | The Kahani dune system sampled in the Namib Desert. (A) Google Maps representation of the sampling site showing the individual soil samples collected. Filled circles represent the 125 soil samples from the 5

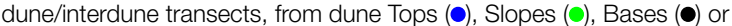
Interdune (๑). E, East; W, West. (B) Photograph of the dune Top (west) devoid of vegetation. (C) Photograph of the dune Slope (W) with sparse perennial grasses (Stipagrostis sabulicola and Trianthema hereroensis). (D) Photograph of the barren Interdune.

$0.45 \mu \mathrm{m}$ Millipore filter (EMD Millipore Corporation, Billerica, MA, USA).

Particle size distributions were determined using the ASTM protocol D422-63 on $50 \mathrm{~g}$ of soil sample (ASTM, 1985). The hydrometer method (Bouyoucos, 1962) was used to measure the size distribution of the silt and clay fractions obtained from the ASTM protocol. Granulometry analysis contributed to the formation of 8 variables: very coarse sand (VCS), coarse sand (CS), medium sand (MS), fine sand (FS), very fine sand (VFS) and the portion of the silt plus clay (SC), silt (ST), and clay (CY).

\section{Fluorescein Di-acetate Degradation Assay}

FDA hydrolysis, as an indicator of general bacterial metabolic activity, was measured using the protocol of Green et al. (2006). $0.5 \mathrm{~g}$ of soil was mixed with $12.5 \mathrm{~mL}$ of sterile phosphate buffered saline (PBS, pH 7.4) and $0.25 \mathrm{~mL}$ of $4.9 \mathrm{mM}$ FDA dissolved in acetone and subsequently incubated at $28^{\circ} \mathrm{C}$ for $1 \mathrm{~h}$ under constant agitation. FDA hydrolysis was stopped by mixing $40 \mu \mathrm{L}$ of acetone with $1 \mathrm{~mL}$ of soil slurry. After centrifugation $(8800 \times$ g, 5 min.) fluorescence was measured with a portable fluorometer (Quantifluor, Promega, Madison, USA), calibrated against a standard curve. FDA activity was expressed as $\mu \mathrm{g}$ fluorescein per $\mathrm{g}$ soil per hour ( $\mu \mathrm{g}$ fluorescein $\mathrm{g}^{-1}$ soil $\mathrm{h}^{-1}$ ).

\section{Metagenomic DNA Extraction, PCR Amplification and T-RFLP}

Metagenomic DNA was extracted from $0.5 \mathrm{~g}$ of soil using the PowerSoil $^{\mathrm{TM}}$ DNA Isolation Kit (MoBio, West Carlsbad, CA, USA) following the manufacturer's instructions.
PCR reactions were carried out in a Thermo Cycler (BioRad) in $50 \mu \mathrm{L}$ final volume reactions containing 1X PCR Buffer A, 1X Enhancer, $0.2 \mathrm{mM}$ each dNTP, $0.5 \mu \mathrm{M}$ of each primer (E9F: 5'-GAGTTTGATCCTGGCTCAG-3'/U1510R: 5' GGTTACCTTGTTACGACTT-3') (Reysenbach and Pace, 1995; Hansen et al., 1998), 4\% DMSO, $0.5 \mathrm{U}$ of KAPA2G Robust DNA polymerase (KAPA, USA) and $10 \mathrm{ng}$ of template DNA. Thermal cycling conditions were as follows: 3 min denaturation at $95^{\circ} \mathrm{C}$ followed by 30 cycles with denaturation at $95^{\circ} \mathrm{C}$ for $30 \mathrm{~s}$, annealing at $55^{\circ} \mathrm{C}$ for $30 \mathrm{~s}$, and elongation at $72^{\circ} \mathrm{C}$ for $90 \mathrm{~s}$ with a final elongation at $72^{\circ} \mathrm{C}$ for $10 \mathrm{~min}$. This reaction yielded $1.5 \mathrm{~kb}$ amplicons.

For T-RFLP analysis, the forward E9F primer was FAMlabeled and the PCR products were purified using the NucleoSpin $\mathrm{Kit}^{\mathrm{TM}}$ (Macherey-Nagel, Germany) and digested overnight using HaeIII (Fermentas, USA). After a second purification, electrophoretic separation of the terminal-restriction fragments (T-RFs) was performed using an ABI3130XL sequencer (Applied Biosystems, USA). The retrieved T-RFLP profiles were analyzed using Peak Scanner 1.0 (Applied Biosystems; http://www. appliedbiosystems.com). True peaks and fragments of similar size were identified and binned using the software $\mathrm{R}$ and Perl (Abdo et al., 2006). The term OTU (Operational Taxonomic Unit) is used to refer to individual terminal restriction fragments (T-RF) in T-RFLP patterns, with recognition that each OTU may comprise more than one distinct bacterial ribotype.

\section{Statistical Analyses}

Principal Component Analyses (PCA) was performed (prcomp $R$ function) on standardized soil chemistry variables and granulometric parameters (Oksanen, 2013). T-RFLP data were Hellinger-transformed (Legendre and Gallagher, 2001) and used to calculate Bray-Curtis dissimilarity matrices, which were further visualized using 3D non-metric multidimensional scaling (3D-nMDS) (Primer 6 software; Primer-E Ltd, UK). Permutational multivariate analysis of variance (PERMANOVA), function Adonis (vegan package for $\mathrm{R}$ ), was used to test for significant differences between sample groups along the dune/interdune transects. Distance based redundancy analysis (dbRDA) was used to determine correlations between bacterial community structures and habitat parameters (e.g., soil chemistry and granulometry) (vegan package for R). Negative eigenvalues were transformed by taking the square root of dissimilarities.

An analysis of multivariate homogeneity of group dispersions (variances) (betadisper function in vegan package for $\mathrm{R}$ ) was used to test if one or more of the dune zones was significantly more variable than the others. The test was performed on standardized soil physico-chemical properties and bacterial community structures (relative abundance of OTUs).

Edaphic variables significantly correlated, or "redundant" (based on PCA analysis), were grouped for dbRDA analysis in order to decrease co-linearity and noise (Table 1) (Legendre and Legendre, 2012), yielding 15 independent variables: $\mathrm{pH}, \mathrm{NO}_{3}^{-}$ $\mathrm{N}, \mathrm{NH}_{4}^{+}-\mathrm{N}, \mathrm{C}, \mathrm{CEC}, \mathrm{Na}, \mathrm{K}, \mathrm{P}, \mathrm{Mg}$ (also representing $\mathrm{Ca}$ ), Fe (also representing $\mathrm{Al}$ and $\mathrm{Mn}$ ), very coarse sand (VCS), coarse 
TABLE 1 | Soil physico-chemistry of the four dune/interdune soil types studied (Top, Slope, Base and Interdune).

\begin{tabular}{|c|c|c|c|c|c|c|}
\hline Variable & Code & RDA group & Top & Slope & Base & Interdune \\
\hline \multicolumn{7}{|l|}{ SOIL CHEMISTRY } \\
\hline Phosphorus (mg kg ${ }^{-1}$ ) & $\mathrm{P}$ & $\mathbf{P}$ & $6.54 \pm 0.69$ & $9.13 \pm 0.30$ & $17.84 \pm 0.99$ & $30.04 \pm 1.11$ \\
\hline Organic carbon (\%) & $\mathrm{C}$ & C & $0.04 \pm 0.01$ & $0.04 \pm 0$ & $0.05 \pm 0.01$ & $0.07 \pm 0.001$ \\
\hline Ammonium $\left(\mathrm{NH}_{4}^{+}-\mathrm{N}\right)\left(\mu \mathrm{g} \mathrm{g}{ }^{-1}\right)$ & $\mathrm{NH} 4$ & $\mathrm{NH} 4$ & $8.74 \pm 0.66$ & $8.23 \pm 0.19$ & $8.58 \pm 0.17$ & $8.67 \pm 0.18$ \\
\hline Nitrate $\left(\mathrm{NO}_{3}^{-}-\mathrm{N}\right)\left(\mu \mathrm{g} \mathrm{g}^{-1}\right)$ & NO3 & NO3 & $6.52 \pm 0.43$ & $6.87 \pm 0.15$ & $6.79 \pm 0.24$ & $6.93 \pm 0.24$ \\
\hline Potassium (mg kg-1) & $\mathrm{K}$ & $\mathrm{K}$ & $2180.30 \pm 44.07$ & $1444.51 \pm 50.49$ & $2175.13 \pm 75.31$ & $2625.23 \pm 36.59$ \\
\hline Magnesium (mg kg-1) & $\mathrm{Mg}$ & $\mathbf{M g}$ & $317.54 \pm 9.01$ & $267.20 \pm 10.65$ & $581.60 \pm 30.52$ & $856.23 \pm 18.94$ \\
\hline Calcium (mg kg ${ }^{-1}$ ) & $\mathrm{Ca}$ & $\mathbf{M g}$ & $4914.84 \pm 220.18$ & $4725.15 \pm 160.22$ & $9375.07 \pm 486.57$ & $13702.48 \pm 470.59$ \\
\hline Sodium (mg kg ${ }^{-1}$ ) & $\mathrm{Na}$ & $\mathrm{Na}$ & $1634.07 \pm 49.26$ & $965.52 \pm 29.39$ & $718.06 \pm 31.19$ & $508.66 \pm 19.96$ \\
\hline $\mathrm{pH}$ & $\mathrm{pH}$ & $\mathrm{pH}$ & $8.59 \pm 0.47$ & $8.30 \pm 0.11$ & $7.82 \pm 0.20$ & $7.75 \pm 0.26$ \\
\hline Cation exchange capacity $\left(\mathrm{cmol}^{+} \mathrm{kg}^{-1}\right)$ & CEC & CEC & $5.31 \pm 0.58$ & $5.11 \pm 0.11$ & $5.69 \pm 0.16$ & $6.40 \pm 0.22$ \\
\hline Aluminium $\left(\mathrm{mg} \mathrm{kg}^{-1}\right)$ & $\mathrm{Al}$ & $\mathrm{Fe}$ & $22.34 \pm 1.08$ & $21.07 \pm 0.59$ & $35.59 \pm 2.23$ & $56.93 \pm 2.47$ \\
\hline Iron $\left(\mathrm{mg} \mathrm{kg}^{-1}\right)$ & $\mathrm{Fe}$ & $\mathrm{Fe}$ & $8.19 \pm 0.24$ & $7.12 \pm 0.14$ & $10.30 \pm 0.6$ & $14.46 \pm 0.91$ \\
\hline Manganese $\left(\mathrm{mg} \mathrm{kg}^{-1}\right)$ & $\mathrm{Mn}$ & $\mathrm{Fe}$ & $3.10 \pm 0.03$ & $3.36 \pm 0.05$ & $5.24 \pm 0.25$ & $8.22 \pm 0.28$ \\
\hline \multicolumn{7}{|l|}{ GRANULOMETRY } \\
\hline Very course sand (\%) & VCS & VCS & $0.05 \pm 0.04$ & $0.34 \pm 0.08$ & $0.63 \pm 0.09$ & $0.58 \pm 0.15$ \\
\hline Coarse sand (\%) & CS & CS & $0.61 \pm 0.84$ & $6.43 \pm 0.7$ & $4.64 \pm 0.83$ & $1.30 \pm 0.12$ \\
\hline Medium sand (\%) & MS & MS & $26.56 \pm 7.42$ & $57.56 \pm 1.43$ & $36.14 \pm 2.78$ & $16.62 \pm 1.20$ \\
\hline Fine sand (\%) & FS & FS & $70.60 \pm 7.32$ & $31.12 \pm 1.46$ & $44.02 \pm 2.22$ & $44.31 \pm 1.26$ \\
\hline Very fine sand (\%) & VFS & VFS & $1.01 \pm 0.28$ & $3.83 \pm 0.31$ & $11.53 \pm 1.44$ & $29.24 \pm 0.98$ \\
\hline Silt \& Clay (\%) & SC & VFS & $0.01 \pm 0.01$ & $0.09 \pm 0.01$ & $1.39 \pm 0.26$ & $4.57 \pm 0.29$ \\
\hline Silt (\%) & ST & VFS & 0.00 & $0.05 \pm 0.03$ & $0.13 \pm 0.06$ & $0.77 \pm 0.15$ \\
\hline Clay (\%) & $\mathrm{CY}$ & VFS & 0.00 & $0.01 \pm 0.01$ & $0.76 \pm 0.1$ & $1 \pm 0$ \\
\hline
\end{tabular}

All values are given as the mean of \pm standard error. In bold are indicated the variables grouped for the RDA analysis presented in Figure 7 .

sand (CS), medium sand (MS), fine sand (FS) and very fine sand (VFS) (representing silt plus clay [SC], silt [ST] and clay $[\mathrm{CY}]$ ). Tukey's HSD (honest significant difference) test was used to test for differences in averaged bacterial activity between dune areas.

\section{Pyrosequencing}

Extracted metagenomic DNA samples from 7 dune zones (Tops E+W, Slopes E+W, Bases $\mathrm{E}+\mathrm{W}$ and Interdune) were pooled. Bacterial 16S rRNA gene amplicons were generated with the primer set 27Fmod (5'-AGRGTTTGATCMTGGCTCAG$\left.3^{\prime}\right) / 519$ Rmodbio $\quad\left(5^{\prime}\right.$-GTNTTACNGCGGCKGCTG-3') and sequenced using a Roche 454 FLX titanium next-generation sequencer by Mr DNA Laboratories (Shallowater, Texas, USA). The sequences are available at the NCBI Sequence Read Archive under the accession number SRP059482.

\section{Pyrosequencing Data Analyses}

Analyses were carried out using the mothur software package (Schloss et al., 2009). Sequences with ambiguity, and/or with homopolymeric stretches longer than $8 \mathrm{bp}$, or shorter than $200 \mathrm{bp}$ were removed with no barcode and primer mismatches accepted. This resulted in reads with sizes ranging from 232 to 314 bp. Chimeras were removed using Perseus (Quince et al., 2011). Sequences were aligned to the reference SILVA database and clustered into operational taxonomic units (OTUs) at the species (97\% similarity) level using the average neighbor settings in mothur. Each OTU was assigned a taxonomic classification with reference to the Ribosomal Database Project (RDP; http:// rdp.cme.msu.edu/index.jsp). Collector's curves were produced using the Chaol diversity index and the coverage using Good's coverage estimator. The community composition of the sand dune zones was compared with a UPGMA tree based on the Jaccard index. Indicator species analysis was conducted using the multipat function of the indicspecies package in $\mathrm{R}$.

\section{Results}

\section{Dune Soil Physico-chemistries}

Principal Component Analysis of 21 physico-chemical parameters from all 125 independent soil samples (Figure 2A) along the five dune-interdune transects (Figure 1) shows Top and Slope samples clearly separated along the PC2 axis (Figure 2A), explaining $10.7 \%$ of the sample variation. Dune Base samples cluster between Slope and Interdune samples (Figure 2A). Top and Slope samples clearly separate from those of the Interdune along PC1, which explains the majority of physico-chemical soil variation $(48.4 \%)$. The most significant result to emerge from our analysis is the observation that each of the four sites examined, namely [dune] Top, Slope, Base and Interdune, was distinct and significantly different (adonis $R^{2}=0.477, p<0.001$ ) with respect to soil physico-chemistry. The test for multivariate homogeneity of group dispersions (betadisper) showed that variations in soil physico-chemical 

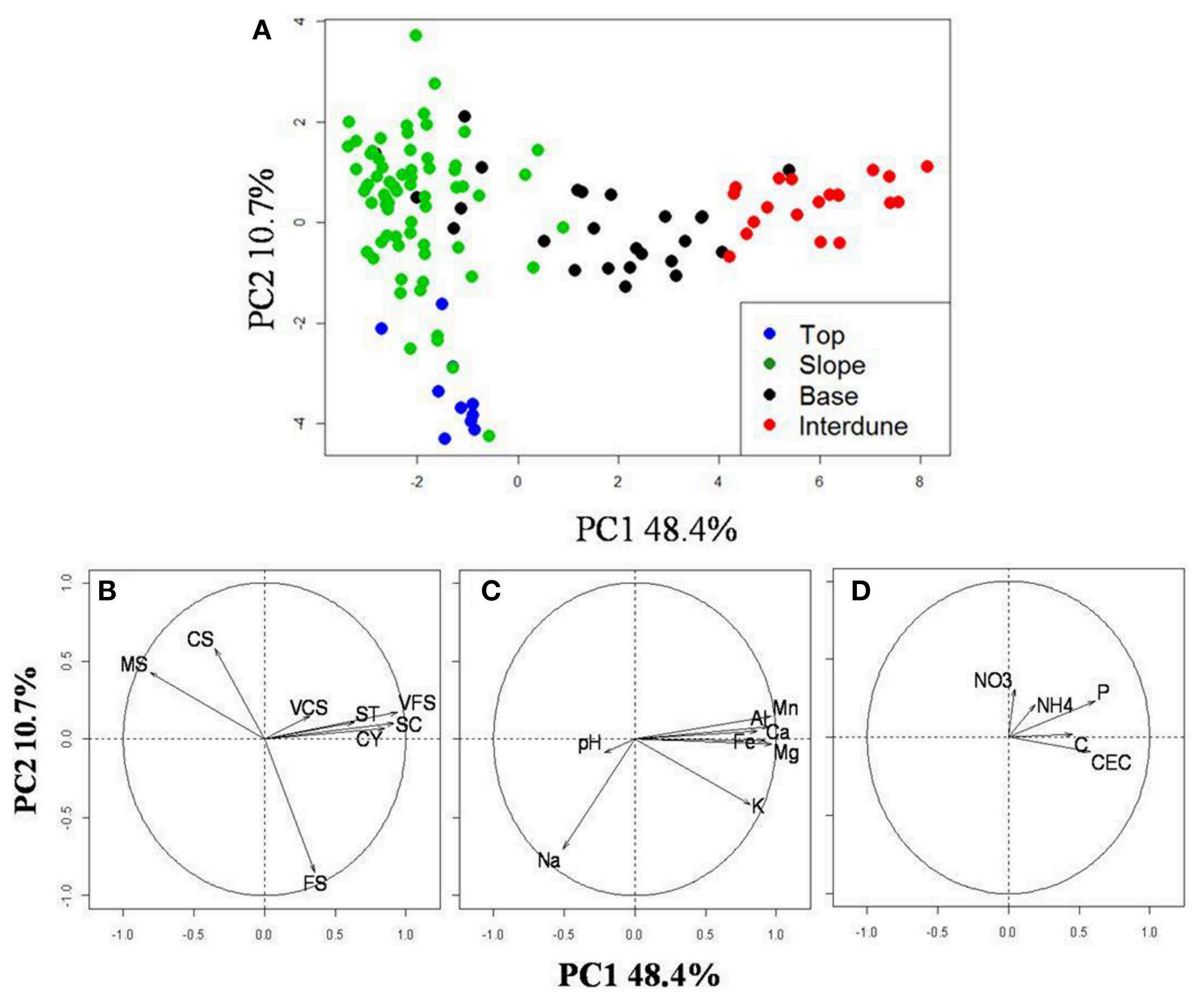

FIGURE 2 | Analysis of the dune edaphic physico-chemical parameters. (A) Principal component analysis (PCA) on 21 standardized edaphic variables from the

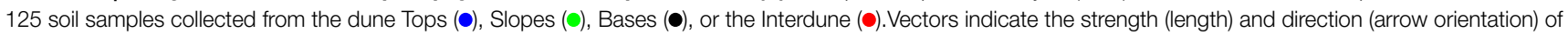
single variable gradient. (B) Soil granulometry gradients; (C) Metals, minerals and pH and (D) the other soil properties measured. The code corresponding to each variable is described in Table $\mathbf{1}$.

properties within dune zones were not significantly different $(p=0.14)$. No statistically significant differences in physicochemical soil properties were found between dunes slopes exposed to different wind regimes (i.e., the lee or stoss slopes) (data not shown).

Soil texture analysis (Figure 2B) also shows separation of the four dune zones with an important fraction of fine sand in the Top zone and proportionally more coarse and medium sands in the Slope and Base areas (Table 1). The Interdune was characterized by a higher proportion of very fine sand, silt and clay than the other zones of the dune (Table 1). Dune Top samples had an elevated $\mathrm{Na}$ content and a higher $\mathrm{pH}$ (Table 1). Concentrations of minerals $(\mathrm{K}, \mathrm{Ca}$ and $\mathrm{Mg}$ ) and metals $(\mathrm{Fe}$, $\mathrm{Al}$ ) were lowest on dune Slopes (Figure 2C) and highest in the Interdune samples (Table $\mathbf{1}$ ) and inversely correlated with $\mathrm{pH}$ (Figure 2C). All other edaphic properties measured, including $\mathrm{C}, \mathrm{P}, \mathrm{pH}, \mathrm{CEC}, \mathrm{NO}_{3}^{-}-\mathrm{N}, \mathrm{NH}_{4}^{+}-\mathrm{N}$, and VCS (Table 1), were only very weakly correlated with the PC1 axis (Figure 2D) and do not appear to contribute to the dune/interdune physico-chemical gradients. Data for the dune Base (Table 1) was generally intermediate between Slope and Interdune. To conclude, this comprehensive dune soil physico-chemistry analyses clearly defined four dune biotopes; i.e., Top, Slope, Base and Interdune.

\section{Dune Zone-specific Bacterial Community Structure and Diversity}

16S rRNA gene T-RFLP analysis yielded between 12 and 105 OTUs per individual sample ( $\alpha$-diversity) for each of the 125 samples. The betadisper function for multivariate homogeneity indicated that variances in the relative abundance of OTUs within dune zones were not significant $(p=0.59)$. Dune Tops showed the lowest bacterial diversity (41 OTUs), while the Slope was the most diverse (80 OTUs) followed by the Base and Interdune with 62 and 53 OTUs, respectively. Only 16 OTUs (15\%) were shared by the bacterial communities of the four dune biotopes (Figure S1A), with samples from the Slope showing the highest number of unique OTUs (16). The 3D-NMDS plot showed that dune bacterial communities cluster according to their soil biotope of origin; i.e., Top, Slope, Base and Interdune (Figure 3). This was confirmed by PERMANOVA analysis (adonis $R^{2}=0.31, p=$ 0.001 ) and consistent with the analysis of soil physico-chemistry (Figure 2A).

Pyrosequencing analysis of $16 \mathrm{~S}$ rRNA gene PCR amplicons yielded a total of 5204 OTUs (defined at $97 \%$ sequence similarity, Table 2; Figure S2B), of which 2741 (47.3\%) were singletons. Dune Tops $(\mathrm{E}+\mathrm{W})$ showed the highest number of unique OTUs (1154) followed by the dune Bases (1170), Slopes (971), and the Interdune (775) samples. Only 88 OTUs (2\%) were shared 


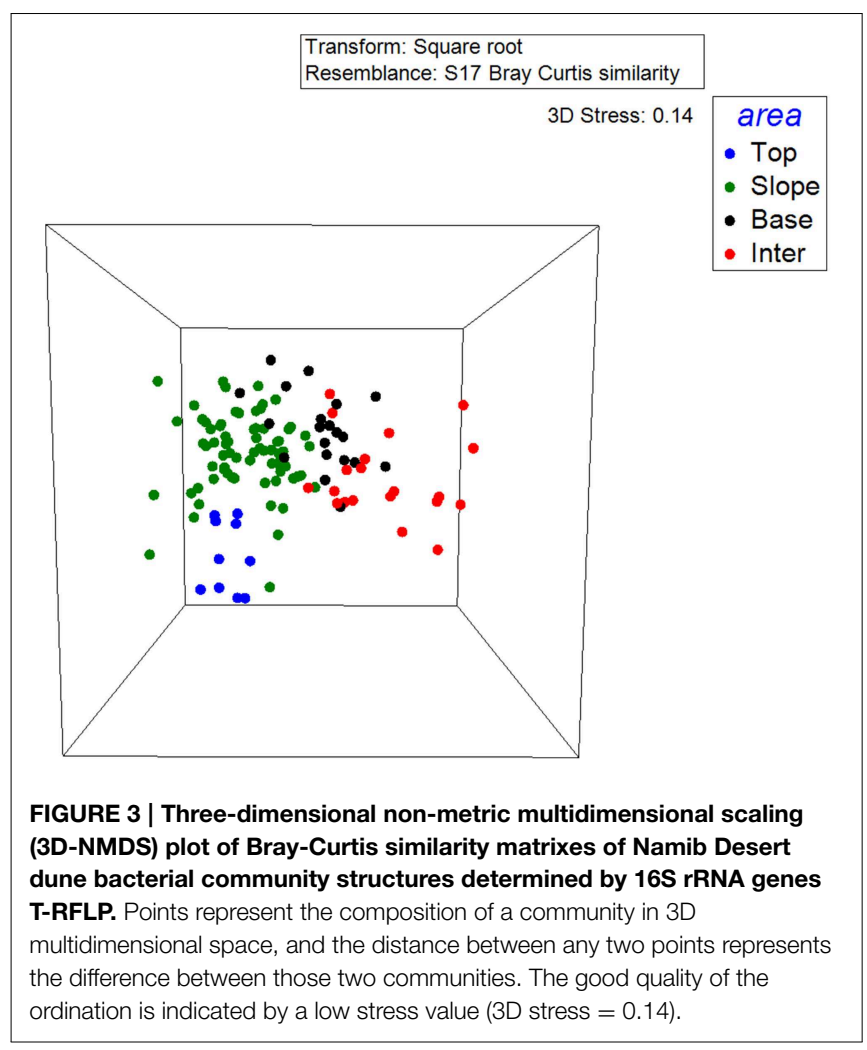

TABLE 2 | Distribution and diversity of OTUs (97\% cut-off) in the seven dune zones studied.

\begin{tabular}{lcccr}
\hline Dune zone & Reads & Coverage & Observed OTUs & Chao1 \\
\hline Top E & 6899 & 0.965 & 782 & 983.71 \\
Top W & 11,709 & 0.964 & 1193 & 1663.27 \\
Slope E & 7089 & 0.939 & 884 & 1461.33 \\
Slope W & 9669 & 0.933 & 1307 & 2234.56 \\
Base E & 7671 & 0.907 & 1329 & 2507.43 \\
Base W & 6836 & 0.905 & 1209 & 2289.56 \\
Interdune & 4653 & 0.836 & 1251 & 2769.02 \\
\hline
\end{tabular}

E, East; W, West.

between the four dune biotopes, which is broadly consistent with the T-RFLP analysis (Figures S1A,B).

After resampling this dataset for sequence consistency $(n=$ 4653 reads), collector's curves using the Chaol index indicated that dune Tops $(\mathrm{E}+\mathrm{W})$ and Slopes $(\mathrm{E}+\mathrm{W})$ samples reached near saturation (Figure S2). UPGMA analysis shows that bacterial communities cluster strongly in relation to their dune biotope of origin (Figure 4), supporting the T-RFLP analysis. However, while bacterial T-RFLP fingerprinting did not differentiate the east/west dune slopes (Figure 3), pyrosequencing analysis detected minor differences (Figure 4) which could be artifactual and related to the low number of samples analyzed.

A total of thirty bacterial phyla were observed in the dune samples (Table S1), with only seven (Acidobacteria, Actinobacteria, Bacteroidetes, Chloroflexi, Deinococcus/Thermus, Firmicutes, and Proteobacteria) showing relative abundances

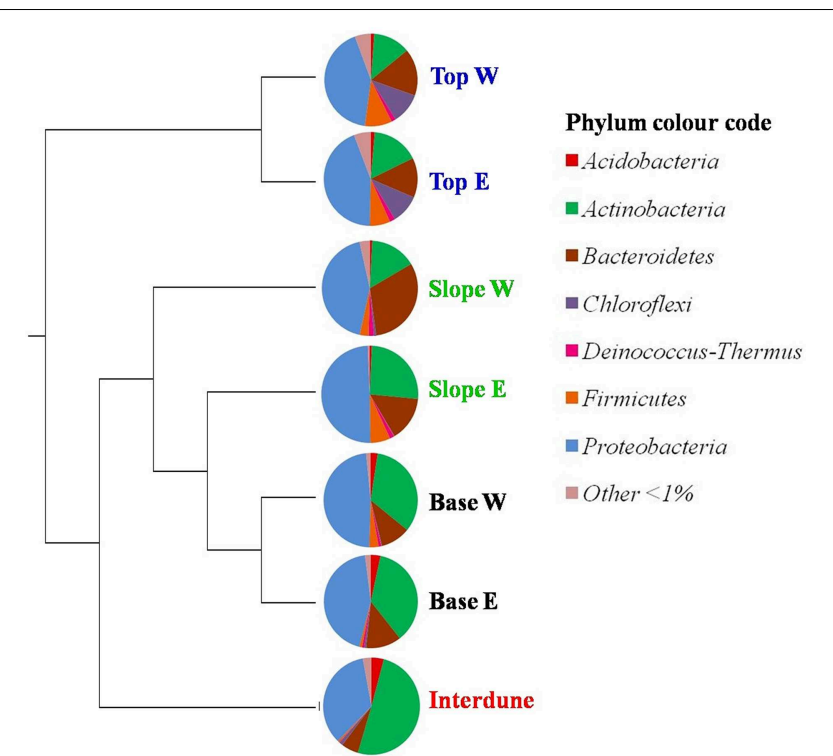

FIGURE 4 | UPGMA cluster analysis comparing the bacterial community composition in the seven a priori defined zones of the Kahani dune system. E, East; W, West. The Pie charts depict dune zone-specific bacterial community composition at the phylum level $(90 \%$ similarity cut-off).

greater than $1 \%$ (Figure 4). Proteobacteria, Actinobacteria, and Bacteroidetes were the dominant phyla in the 7 dune environments studied (Table S1). Bacterial phyla habitatfiltering could be observed with Proteobacteria dominating sand dune samples (i.e., Top, Slope and Base), ranging from 42 to $49 \%$, and Actinobacteria dominating the Interdune biotope (51\%; Figure 4). Moreover, the Chloroflexi, Firmicutes, and Acidobacteria (Figure 4) as well as the Alpha-, Beta-, Gamma-, and Deltaproteobacteria (Figure 5) displayed dune habitat-specific relative abundances: Chloroflexi, Firmicutes, Alpha-, Gamma-, and Delta-proteobacteria presented decreasing abundances from dune Top to the Interdune, while Acidobacteria and Betaproteobacteria presented the opposite trend (Figure 4). Similarly, the three most abundant genera of the dominant Actinobacteria (Geodermatophilus sp., Blastococcus sp., and Arthrobacter sp.) and Proteobacteria (Microvirga sp., Massilia sp., and Novosphingobium sp.) phyla displayed dune habitat specific abundances (Table S2). Altogether, these results strongly suggest habitat-filtration to be a determining process defining dune bacterial community assemblies.

This is confirmed by the fact that, apart from the dune Tops, each dune zone presented different and significantly associated $(p<0.05)$ bacterial indicator species (Dufrêne and Legendre, 1997). Two actinobacterial OTUs were associated with the Interdune: OTU24 from the genus Geodermatophilus sp. and OTU88, a Modestobacter sp. Three actinobacterial genera were also significantly linked to the eastern dune Slope (Kineococcus sp. [OTU73 and OTU77], Arthrobacter sp. [0TU16] and Rathayibacter sp. [0TU46]). Contrastingly, the two west dune slope indicator species were from the Flavisolibacter sp. (OTU6) and Microvirga sp. (OTU23) genera. Finally the dune 


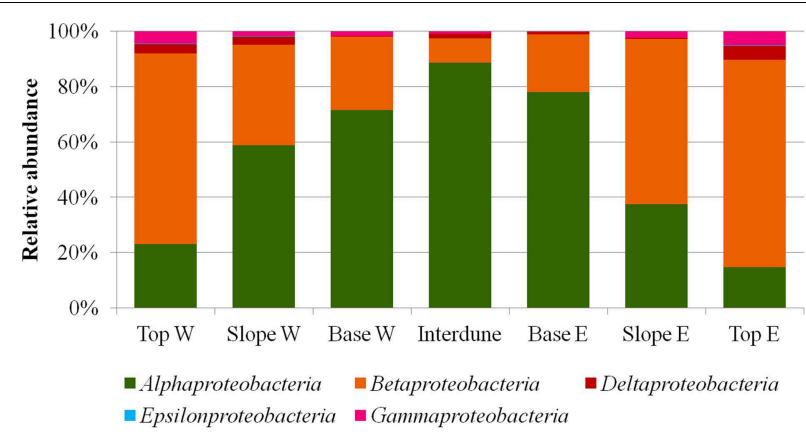

FIGURE 5 | Relative abundances (\%) of the different proteobacterial classes in the seven a priori defined zones of the Kahani dune system.

Bases (east and west) were characterized by indicator species OTU74 from the Acidobacteria Gp16 class and OTU85 from the genus Kineococcus sp.

\section{Dune Zone-specific Metabolizing Bacterial Community}

FDA hydrolysis was used as a proxy for the active bacterial metabolism (Chrzanowski et al., 1984). Active bacterial communities were detected in all dune areas studied (Figure 6), with the highest activity detected in the Interdune samples (average values $0.7-0.75 \mu \mathrm{g}$ fluorescein $\mathrm{g}^{-1}$ soil $\mathrm{h}^{-1}$ ). Lowest activity was observed in Top and Slope samples $(0.05-0.15 \mu \mathrm{g}$ fluorescein $\mathrm{g}^{-1}$ soil $^{-1}$ ) with Base samples showing intermediate values $\left(0.15-0.4 \mu \mathrm{g}\right.$ fluorescein $\mathrm{g}^{-1}$ soil $\left.\mathrm{h}^{-1}\right)$. The results of the Tukey's HSD test on the FDA hydrolysis data indicated that there were only three statistically distinct functional bacterial communities in the dune system: Interdune, Base and Slope/Top (Figure 6).

\section{Identification of Environmental Factors Shaping Dune Bacterial Community Structures}

To further investigate relationships between abiotic factors and bacterial community structure (i.e., T-RFLP results), we performed redundancy analysis (RDA; Figure 7). RDA indicated that of the 21 soil attributes measured, 15 parameters were significant in explaining bacterial community structure variability $(p<0.01)$. However, taken together they only explain $21 \%$ of this variability. These included mineral [Na, $\mathrm{K}, \mathrm{P}, \mathrm{NH}_{4}$ ], metallic [Fe, $\left.\mathrm{Mn}, \mathrm{Al}\right]$ and granulometry factors [VCS, CS, MS, FS and (VFS/SC/ST/CY)], and nutrients [P, $\left.\mathrm{NH}_{4}\right]$. Particle size distribution of the sand dune soils was an important environmental determinant to emerge from the RDA analysis. Our data (Table 1) show very clear grain size segregation, with the finest sands, silts and clays predominantly in the Interdune samples and the medium and coarser grained sands on the dunes themselves. The data indicated that fine grains, silts and clays [VFS, SC, ST, CY] are positively correlated with metals $[\mathrm{Fe} / \mathrm{Mn} / \mathrm{Al}]$, minerals $[\mathrm{Ca} / \mathrm{Mg}]$ and some nutrients $\left(\mathrm{C}, \mathrm{P}, \mathrm{NO}_{3}^{-}\right.$$\mathrm{N}, \mathrm{NH}_{4}^{+}-\mathrm{N}$ ) (Figure 7 and Figure S1C).

Two main clusters of bacterial community samples were separated along the RDA axis1 as shown on Figure 7: the dune

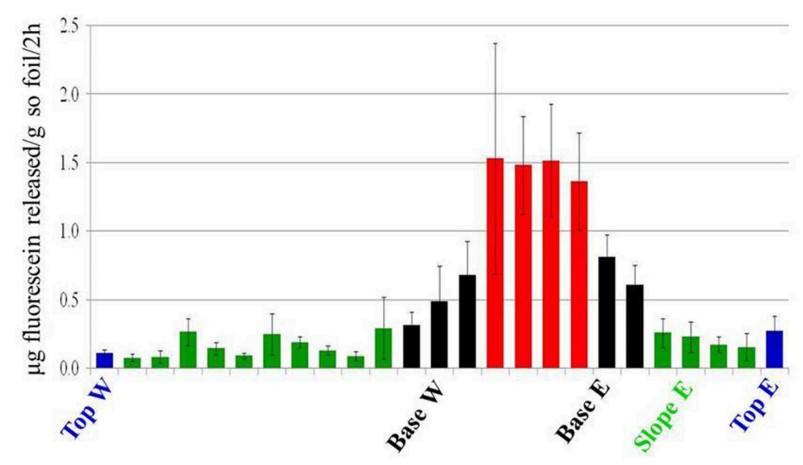

FIGURE 6 | Fluorescein di-acetate (FDA) hydrolysis values showing the average potential bacterial activity ( $\mu$ g fluorescein $\mathrm{g}^{-1}$ soil $\mathrm{h}^{-1}$ ) along the dune/interdune transect. Each column of the histogram shows the mean and standard deviation of the values from the 5 parallel samples of each transect. The transect profile is represented from west $(\mathrm{W})$ to east $(\mathrm{E})$. Blue, Top; Green, Slope; Black, Base; Red, Interdune.

Base and Interdune bacterial community samples (cluster 1) and the dune Slope and Top samples (cluster 2). The bacterial community structures from cluster 1 were mainly driven by VFS, VCS and $\mathrm{NH}_{4}^{+}-\mathrm{N}, \mathrm{K}, \mathrm{Fe}$, and $\mathrm{P}$ contents while those of cluster 2 by MS and Na contents. Communities from both clusters were further separated along the RDA axis2 according to their dune biotope of origin, with granulometry parameters [FS and CS] differentiating the structures of the Interdune and dune Base communities as well as the ones from the dune Top and Slope (Figure 7).

Overall, these results demonstrate that environmental gradients in the four defined biotopes (i.e., dune Top, Slope, Base, and Interdune) significantly impact the bacterial community structures of dune/interdune transects.

\section{Discussion}

The geomorphology and the macro-fauna/flora of the $34,000 \mathrm{~km}^{2}$ area of the Namib Sand Sea have been extensively studied (Seely and Pallett, 2008; Livingstone, 2013). However, arguably the most productive component of this depauperate environment, the edaphic microbial community (Makhalanyane et al., 2015), has received little attention at either local (a unique dune system) or regional (multiple dune systems) scales (Jacobson, 1997). Moreover, the drivers of desert dune microbial community assembly generally remain unclear.

This study was designed to evaluate the importance of deterministic processes (e.g., habitat filtering) in influencing bacterial communities in the Namib Sand Sea dune system. We provide a comprehensive analysis of a localized site, with 125 soil samples collected from five parallel $2 \mathrm{~km}$ dune/interdune transects. All samples were characterized by $16 \mathrm{~S}$ rRNA gene TRFLP fingerprinting and the determination of multiple physicochemical parameters. The use of multiple parallel transects was intended to minimize the effects of local heterogeneity and spatial unevenness, and to generate statistically robust and representative datasets (Prosser, 2010). 16S rRNA gene 


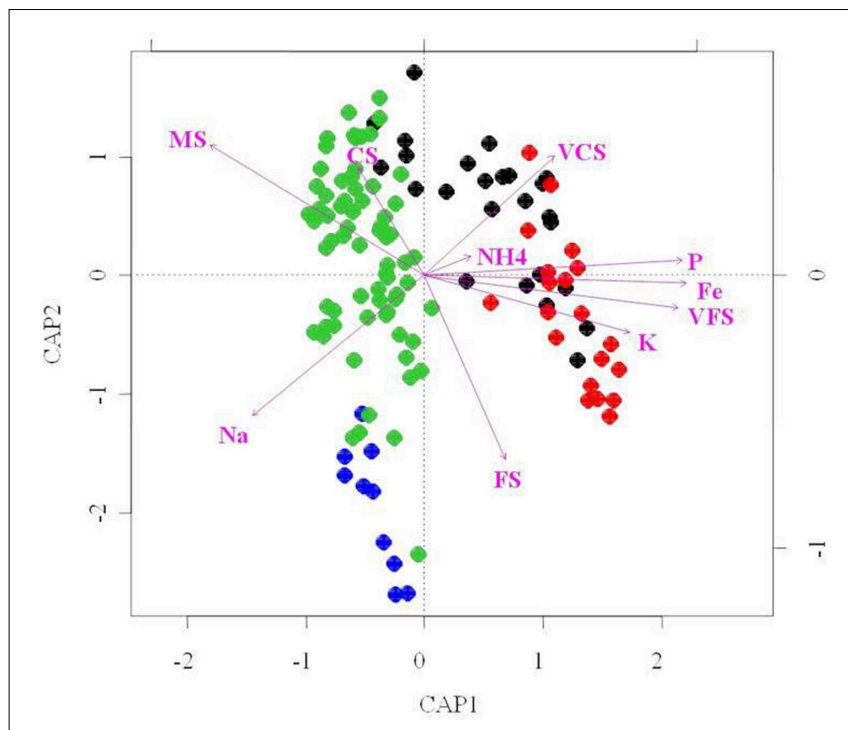

FIGURE 7 | Redundancy analysis (RDA) bi-plot of bacterial diversity and physico-chemical parameters. Only the environmental variables that significantly explained variability in microbial community structures are fitted to the ordination (arrows). The direction of the arrows indicates the direction of maximum change of that variable, whereas the length of the arrow is proportional to the rate of change. Blue, dune Top; Green, dune Slope; Black, dune Base; Red, Interdune.

amplicons from representative samples were also pyrosequenced to provide more insight into the phylogenetic composition of dune/interdune transects and evaluate if $a$ priori defined niches would present different community assemblages.

\section{Soil Properties of the Namib Desert Dune/Interdune Transect Define Four Biotopes}

The physico-chemical characteristics of soils along the Namib Desert dune-interdune transects clustered into four distinct datasets (Figure 2; Table 1): dune Top, Slope, Base, and Interdune. Granulometry data were typical for Namib Desert dune systems, with the highest proportion of fine sand on dune summit; a phenomenon commonly attributed to segregation of aeolian deposits from the gravel Interdune zone, and general concentration of coarse sands toward the dune Base (Lancaster, 1981). High Na content in the dune top samples is thought to be the result of salt capture from marine fog, the commonest source of moisture in this particular Namib Desert environment (Abrams et al., 1997; Hachfeld, 2000; Eckardt et al., 2013b). The high metal content recorded in the Interdune zone is likely to reflect the underlying geology, which includes red Tsondab sandstone (Besler, 1996), but may also be a consequence of the higher proportion of the fine soil particle fractions (VFS, SC, ST, and $\mathrm{CY}$ ), the presence of which reduce percolation and enhance mineral accumulation and persistence (Chamizo et al., 2012).

\section{Bacterial Community Structures, Diversities and Potential Function Suggest Habitat Filtration in Dune/Interdune Transects}

A total of 30 bacterial phyla were detected in Namib Desert dune soils and all samples were dominated by Proteobacteria,
Actinobacteria, and Bacteroidetes, which has also been observed in other desert systems (Makhalanyane et al., 2015). Namib Desert dune samples showed similar phylogenetic profiles to dune systems from the Gobi (Mongolia) and Taklamaken (China) deserts (An et al., 2013), but with lower OTU diversity than dune slope and interdune of the Gurbantunggut (China) desert (Li et al., 2015). The latter, however, was characterized by cyanobacteria-rich biological soil crusts (BSC), which were not observed in the Namib Sand Sea at the time of sampling.

Both 16S rRNA gene T-RFLP (Figures 3, 7; Figure S1A) and pyrosequencing (Figures 4, 5; Table 1 and Table S1; Figure S1B) data strongly support the concept of niche-partitioning/habitatfiltering in the Namib Desert dune/interdune system (Dumbrell et al., 2010), as both the structures and phylogenetic compositions of the bacterial communities demonstrated similar clustering than those of the physico-chemical characteristics (Figure 2). This was further supported by the low number of OTUs (15\% from T-RFLP and 2\% from pyrosequencing) shared by all dune biotopes (Figure S1). Taken together, these results strongly imply that habitat filtering, possibly via environmental physico-chemical gradients, is a major driver of bacterial community composition in dune ecosystems (Brankatschk et al., 2013; Liu et al., 2014).

While bacterial community T-RFLP fingerprinting and pyrosequencing showed highly comparable overall microbial community patterns (Figures 3,4 ), pyrosequencing data showed minor differences in bacterial community structures between the east and west dune slopes (Figure 4). As the edaphic characteristics of these dune aspects were not significantly different, it is suggested that other environmental parameters, such as aeolian disturbance (Thomas and Dougill, 2007) or solar radiation (Jacobs and Sundin, 2001) differentials, could account for these differences.

\section{Dune/Interdune Transect Habitat-filters}

Distance based RDA analysis showed that 15 edaphic parameters, including mineral $[\mathrm{Na}, \mathrm{K}]$, metallic $[\mathrm{Fe} / \mathrm{Mn} / \mathrm{Al}]$ and granulometry factors [VCS, CS, MS, FS and (VFS/SC/ST/CY)], and nutrients $\left[\mathrm{P}, \mathrm{NH}_{4}\right]$ were strongly correlated with bacterial community structure variability in dune soil environments (Figure 7, Table 1). Using $\mathrm{Na}$ as a proxy for soil salinity, we conclude that this factor plays an important role in directing dune microbial community compositions. Variations in salinity have previously been shown to be a strong bacterial habitat filter in Namib Desert gravel plain soils and hypoliths (Stomeo et al., 2013). The importance of soluble salts in dictating bacterial species abundance is supported by the observation that halotolerant microorganisms are readily isolated from interdune soils in the Negev Desert (Yu and Steinberger, 2012b) and Thar Desert sands (Sharma et al., 2013).

The role of $\mathrm{K}$ as a habitat filter may be related to intracellular osmoregulation (Fierer et al., 2012) while that of metals [Fe/Mn/Al] could be linked to their bioavailability, typically controlled by solubility and/or adsorption onto mineral surfaces (Cornell and Schwertmann, 2003). In this resource-limited desert environment, it was unsurprising to identify the nutrients $\mathrm{P}$ 
and $\mathrm{NH}_{4}$ as environmental drivers of dune bacterial community structures. The bioavailability of phosphorus and nitrogen has indeed previously been found to impact desert soil microbial functional and structural properties (Austin et al., 2004; Bell et al., 2014). We note that the use of P-Bray I to quantify total $\mathrm{P}$ underestimated the $\mathrm{P}$ contents in these mildly alkaline soils (Bowman and Vigil, 2002). In future studies, a more appropriate method such as the sodium bicarbonate procedure (Olsen et al., 1954) should be used to properly evaluate the bioavailable $P$ contents in these desert soils and its potential as a factor shaping dune bacterial communities. The precise role of these dbRDAdetermined environmental parameters in shaping dune bacterial community structures and functions could be further tested in controlled experiments (e.g., micro- or mesocosms; Lan et al., 2014).

The single most important environmental determinant to emerge from these data is the desert dune soil particle size distribution. Specific microbe-particle associations have already been demonstrated (e.g., Zhang et al., 2007; Carson et al., 2010). This could be related to the fact that differences in soil structure can manipulate soil nutrient status (Zhang et al., 2007; Carson et al., 2010). Our data do indicate that fine grains, silts and clays [VFS, SC, ST, CY] are positively correlated with metals $[\mathrm{Fe} / \mathrm{Mn} / \mathrm{Al}]$, minerals $[\mathrm{Ca} / \mathrm{Mg}]$ and some nutrients $(\mathrm{C}, \mathrm{P}$, $\left.\mathrm{NO}_{3}^{-}-\mathrm{N}, \mathrm{NH}_{4}^{+}-\mathrm{N}\right)$ (Figure 2). This suggests that the relationship between bacterial diversity, soil structure and nutrient contents needs further investigation in dune soils as subtle differences in sand mineralogy and micronutrient contents has been shown to significantly impact edaphic community structuring (Welz et al., 2014).

We noted that $79 \%$ of the variation in soil bacterial community structures remains unexplained (Figure 5), although this is not uncommon in microbial ecology studies (e.g., Cottenie, 2005; Dumbrell et al., 2010). The high proportion of unaccounted variation might be attributed to other deterministic environmental factors not recorded in this study (e.g., wind transport, effect of sand burial stress or changes in humidity, and/or other soil physicochemistries) or the effects of microbial interactions (Vellend, 2010; Caruso et al., 2011). We also cannot rule out the role of stochastic processes in the assembly of dune communities, as, at a global scale, it has been shown significantly drive bacterial community assembly in deserts (Caruso et al., 2011).

The Namib Desert sand dunes are physically dynamic environments with high levels of wind erosion and dispersion (Eckardt et al., 2013a; Livingstone, 2013). It could be argued that in apparently well-connected habitats such as those of the Namib Sand Sea, dispersal rates should be sufficiently high so as to lead to homogenization of microbial communities due to mass-mixing effects (Leibold and Norberg, 2004). However, our bacterial fingerprint results and phylogenetic analyses show that only a limited number of OTUs were shared across all four dune habitats and that the number of OTUs unique to each area and OTUs shared by contiguous habitats was also low (Figure S1). This suggests that aeolian transport and cellular dispersal is not a substantial driver of sand dune bacterial community structure. However, it cannot be completely excluded. Indeed, in the dune Top zone, which experiences the highest wind disturbance (Eckardt et al., 2013a), the lowest levels of bacterial activity were observed (as determined by fluorescein diacetate hydrolysis: Figure 6) and no indicator species was identified. It could be argued that this zone does not represent a stable community and that the detected activity could be derived from microorganisms bound to wind-transported mineral grains (Yamaguchi et al., 2012).

\section{Phylogenetic Composition of Namib Desert Dune Biotope Soils in Relation to Pedogenesis and Ecosystem Development}

Many studies have shown that microbial communities evolve with the development of ecosystems, over short (weeks) or long (years/hundreds of years) temporal scales (e.g., Ramond et al., 2012; Ferrenberg et al., 2013; Jangid et al., 2013). For example, in a 6500 year dune soil chronosequence, Betaproteobacteria, Bacteroidetes, Actinobacteria, Cyanobacteria, and Firmicutes were shown to dominate "young soil ecosystems"; i.e., recent or often-disturbed soil environments (Jangid et al., 2013). Contrastingly, the relative abundances of Acidobacteria, Alphaproteobacteria, and Planctomycetes were higher in "aged soils"; i.e., more structured and stabilized environments (Jangid et al., 2013). Similarly, continuous physical disturbance has been shown to influence community composition in cold desert biocrust soils (Kuske et al., 2012), with continuously trampled soils showing decreasing cyanobacterial abundances with corresponding increases in Actinobacteria, Chloroflexi, and Bacteroidetes, compared to undisturbed soils.

As previously observed in a 6500 year dune soil chronosequence (Jangid et al., 2013), Betaproteobacteria, Bacteroidetes, and Firmicutes were more abundant in the more dynamic dune Tops and Slopes, while the relative abundances of Acidobacteria and Alphaproteobacteria were higher in the more stable Interdune soils. Cyanobacteria were almost exclusively detected in the stable Interdune soils (albeit in proportionally very low percentages: $0.46 \%$ ), which were dominated by Actinobacteria, comprising over $50 \%$ of the interdune community (Table S1). Our results are remarkably consistent with the comparative data obtained from disturbed and stable biocrust systems (Kuske et al., 2012) and suggest that the degree of stability or perturbation of the Namib Desert soils may be one of the key deterministic factors contributing to the high proportion of unaccounted variation in community structure of the Namib Desert dune systems.

\section{Concluding Remarks}

Our results clearly showed that, in dune/interdune transects of the Namib Desert, soil physico-chemistry define four dune zones, namely the dune Tops, Slopes, Bases and Interdune. Furthermore, we demonstrated that each of these zones presented unique bacterial communities. Altogether, this strongly suggested that these communities were selected through habitat filters, i.e., environmental deterministic 
factors (Dumbrell et al., 2010). The measurement of 21 environmental factors enabled us to define that habitat stability, soil texture and mineral and nutrient contents were influencing dune/interdune transect bacterial communities. However, almost $80 \%$ of the dune/interdune bacterial community's variability remained unexplained indicating that other unmeasured deterministic factors or processes, such as species' interaction, dispersal and/or stochasticity (Vellend, 2010), may be involved. Consequently, to further investigate bacterial community assembly and its driver(s) in dune systems, such study should be extended to multiple dune/interdune environments.

\section{Author Contributions}

SR, JR, and DC designed the experiment. SR performed the lab work and analyzed the data with some help from JR. JR, $\mathrm{BJ}, \mathrm{SR}, \mathrm{MS}$, and DC participated in writing the manuscript.

\section{References}

Abdo, Z., Schüette, U. M. E., Bent, S. J., Williams, C. J., Forney, L. J., and Joyce, P. (2006). Statistical methods for characterizing diversity of microbial communities by analysis of terminal restriction fragment length polymorphisms of 16S rRNA genes. Environ. Microbiol. 8, 929-938. doi: 10.1111/j.1462-2920.2005.00959.x

Abrams, M. M., Jacobson, P. J., Jacobson, K. M., and Seely, M. K. (1997). Survey of soil chemical properties across a landscape in the Namib Desert. J. Arid Environ. 35, 29-38. doi: 10.1006/jare.1995.0139

American Society for Testing Materials (ASTM). (1985). Standard Test Method for Particle-size Analysis of Soils D422-63 (1972). Philadelphia, PA: ASTM.

An, S., Couteau, C., Luo, F., Neveu, J., and DuBow, M. S. (2013). Bacterial diversity of surface sand samples from the Gobi and Taklamaken Deserts. Microb. Ecol. 66, 850-860. doi: 10.1007/s00248-013-0276-2

Andrew, D. R., Fitak, R. R., Munguia-Vega, A., Racolta, A., Martinson, V. G., and Dontsova, K. (2012). Abiotic factors shape microbial diversity in Sonoran Desert soils. Appl. Environ. Microbiol. 78, 7527-7537. doi: 10.1128/AEM. 01459-12

Austin, A. T., Yahdjian, L., Stark, J. M., Belnap, J., Porporato, A., Norton, U., et al. (2004). Water pulses and biogeochemical cycles in arid and semiarid ecosystems. Oecolagia 141, 221-235. doi: 10.1007/s00442-0041519-1

Bell, C. W., Tissue, D. T., Loik, M. E., Wallenstein, M. D., Acosta-Martinez, V., Erickson, R. A., et al. (2014). Soil microbial and nutrient responses to 7 years of seasonally altered precipitation in a Chihuahuan Desert grassland. Glob. Change Biol. 20, 1657-1673, doi: 10.1111/gcb.12418

Besler, H. (1996). The Tsondab Sandstone in Namibia and its significance for the Namib Erg. S. Afr. J. Geol. 99, 77-87.

Bouyoucos, G. J. (1962). Hydrometer method improved for making particle size analyses of soils. Agro. J. 54, 464-473. doi: 10.2134/agronj1962.00021962005400050028x

Bowman, R. A., and Vigil, M. F. (2002). Soil testing for different phosphorus pools in cropland soils of the Great Plains. J. Soil Water Conserv. 57, 479-485.

Brankatschk, R., Fischer, T., Veste, M., and Zeyer, J. (2013). Succession of N cycling processes in biological soil crusts on a Central European inland dune. FEMS Microbiol. Ecol. 83, 149-160. doi: 10.1111/j.1574-6941.2012.01459.x

Bray, R. H., and Kurtz, L. T. (1945). Determination of total organic and available forms of phosphorus in soils. Soil Sci. 59, 39-45. doi: 10.1097/00010694194501000-00006

Carson, J. K., Gonzalez-Quiñones, V., Murphy, D. V., Hinz, C., Shaw, J. A., and Gleeson, D. B. (2010). Low pore connectivity increases bacterial diversity in soil. Appl. Environ. Microbiol. 76, 3936-3942. doi: 10.1128/AEM.03085-09
DC contributed to the reagents, materials and analysis tools required. MS' field knowledge was necessary in the design experiment.

\section{Acknowledgments}

The authors thank the University of Pretoria Genomics Research Institute and the National Research Foundation (NRF) of South Africa for financial support. We also thank all the members of CMEG who assisted with fieldwork in the Namib Desert. Finally, we thank the reviewers as for their very constructive remarks that improved the manuscript.

\section{Supplementary Material}

The Supplementary Material for this article can be found online at: http://journal.frontiersin.org/article/10.3389/fmicb. 2015.00845

Caruso, T., Chan, Y., Lacap, D. C., Lau, M. C. Y., McKay, C. P., and Pointing, S. B. (2011). Stochastic and deterministic processes interact in the assembly of desert microbial communities on a global scale. ISME J. 5, 1406-1413. doi: 10.1038/ismej.2011.21

Chamizo, S., Cantón, Y., Miralles, I., and Domingo, F. (2012). Biological soil crust development affects physicochemical characteristics of soil surface in semiarid ecosystems. Soil Biol. Biochem. 49, 96-105. doi: 10.1016/j.soilbio.2012. 02.017

Chrzanowski, T. H., Crotty, R. D., Hubbard, J. G., and Welch, R. P. (1984). Applicability of the fluorescein diacetate method of detecting active bacteria in freshwater. Microb. Ecol. 10, 179-185. doi: 10.1007/BF020 11424

Cornell, R. M., and Schwertmann, U. (2003). The Iron Oxides: Structure Properties Reactions Occurrences and Uses. Hoboken, NJ: John Wiley \& Sons.

Cottenie, K. (2005). Integrating environmental and spatial processes in ecological community dynamics. Ecol. Lett. 8, 1175-1182. doi: 10.1111/j.14610248.2005.00820.x

Dufrêne, M., and Legendre, P. (1997). Species assemblages and indicator species: the need for a flexible asymmetrical approach. Ecol. Monogr. 67, 345-366. doi: $10.2307 / 2963459$

Dumbrell, A. J., Nelson, M., Helgason, T., Dytham, C., and Fitter, A. H. (2010). Relative roles of niche and neutral processes in structuring a soil microbial community. ISME J. 4, 337-345. doi: 10.1038/ismej.2009.122

Eckardt, F. D., Livingstone, I., Seely, M., and Von Holdt, J. (2013a). The surface geology and geomorphology around Gobabeb, Namib Desert, Namibia. Geogr. Ann. Ser. Phys. Geogr. 95, 271-284. doi: 10.1111/geoa. 12028

Eckardt, F. D., Soderberg, K., Coop, L. J., Muller, A. A., Vickery, K. J., Grandin, R. D., et al. (2013b). The nature of moisture at Gobabeb, in the central Namib Desert. J. Arid Environ. 93, 7-19. doi: 10.1016/j.jaridenv.2012.01.011

Eckardt, F. D., and Spiro, B. (1999). The origin of sulphur in gypsum and dissolved sulphate in the Central Namib Desert, Namibia. Sediment. Geol. 123, 255-273. doi: 10.1016/S0037-0738(98)00137-7

Eckert, D., and Sims, J. T. (1995). Recommended soil pH and lime requirement tests recommended soil testing procedures for the north eastern United States. Northeast Regional Bull. 493, 11-16.

Ferrenberg, S., O’Neill, S. P., Knelman, J. E., Todd, B., Duggan, S., Bradley, D., et al. (2013). Changes in assembly processes in soil bacterial communities following a wildfire disturbance. ISME J. 7, 1102-1111. doi: 10.1038/ismej.2013.11

Fierer, N., Leff, J. W., Adams, B. J., Nielsen, U. N., Bates, S. T., Lauber, C. L., et al. (2012). Cross-biome metagenomic analyses of soil microbial communities and their functional attributes. Proc. Natl. Acad. Sci. U.S.A. 109, 21390-21395. doi: $10.1073 /$ pnas. 1215210110 
Gombeer, S., Ramond, J.-B., Eckardt, F. D., Seely, M., and Cowan, D. A. (2015). The influence of surface soil physicochemistry on the edaphic bacterial communities in contrasting terrain types of the Central Namib Desert. Geobiology 13, 494-505. doi: 10.1111/gbi.12144

Green, V. S., Stott, D. E., and Diack, M. (2006). Assay for fluorescein diacetate hydrolytic activity: optimization for soil samples. Soil Biol. Biochem. 38, 693-701. doi: 10.1016/j.soilbio.2005.06.020

Hachfeld, B. (2000). Rain fog and species richness in the Central Namib Desert in the exceptional rainy season of 1999/2000. Dinteria 26, 113-146.

Hansen, M. C., Tolker-Nielsen, T., Givskov, M., and Molin, S. (1998). Biased 16S rDNA PCR amplification caused by interference from DNA flanking the template region. FEMS Microbiol. Ecol. 26, 141-149. doi: 10.1111/j.15746941.1998.tb00500.x

Jacobs, J. L., and Sundin, G. W. (2001). Effect of solar UV-B radiation on a phyllosphere bacterial community. Appl. Environ. Microbiol. 67, 5488-5496. doi: 10.1128/AEM.67.12.5488-5496.2001

Jacobson, K., van Diepeningen, A., Evans, S., Fritts, R., Gemmel, P., Marsho, C., et al. (2015). Non-rainfall moisture activates fungal decomposition of surface litter in the Namib Sand Sea. PLoS ONE 10:e0126977. doi: 10.1371/journal.pone. 0126977

Jacobson, K. M. (1997). Moisture and substrate stability determine VA-mycorrhizal fungal community distribution and structure in an arid grassland. J. Arid Environ. 35, 59-76. doi: 10.1006/jare.1995.0140

Jacobson, K. M., and Jacobson, P. J. (1998). Rainfall regulates decomposition of buried cellulose in the Namib Desert. J. Arid Environ. 38, 571-583. doi: 10.1006/jare.1997.0358

Jangid, K., Whitman, W. B., Condron, L. M., Turner, B. L., and Williams, M. A. (2013). Progressive and retrogressive ecosystem development coincide with soil bacterial community change in a dune system under lowland temperate rainforest in New Zealand. Plant Soil. 367, 235-247. doi: 10.1007/s11104-013$1720-2$

Keeney, D. R., and Nelson, D. W. (1982). "Nitrogen-inorganic forms," in Methods of Soil Analysis Part 2 Chemical and Microbiological Properties, ed A. G. Norman (Madison, WI: American Society of Agronomy), 643-698.

Kuske, C. R., Yeager, C. M., Johnson, S., Ticknor, L. O., and Belnap, J. (2012). Response and resilience of soil biocrust bacterial communities to chronic physical disturbance in arid shrublands. ISME J. 6, 886-897. doi: 10.1038/ismej.2011.153

Lan, S., Zhang, Q., Wu, L., Liu, Y., Zhang, D., and Hu, C. (2014). Artificially accelerating the reversal of desertification: cyanobacterial inoculation facilitates the succession of vegetation communities. Environ. Sci. Technol. 48, 307-315. doi: $10.1021 / \mathrm{es} 403785 \mathrm{j}$

Lancaster, N. (1981). Grain size characteristics of Namib Desert linear dunes. Sedimentology 28, 115-122. doi: 10.1111/j.1365-3091.1981.tb0 1668. $\mathrm{x}$

Lancaster, N. (1985). Winds and sand movements in the Namib Sand Sea. Earth Surf. Process. Landforms 10, 607-619. doi: 10.1002/esp.3290100608

Legendre, P., and Gallagher, E. (2001). Ecologically meaningful transformations for ordination of species data. Oecologia 129, 271-280. doi: 10.1007/s004420100716

Legendre, P., and Legendre, L. F. (2012). Numerical Ecology. Amsterdam: Elsevier.

Leibold, M. A., and Norberg, J. (2004). Biodiversity in metacommunities: plankton as complex adaptive systems? Limnol. Oceanogr. 49, 1278-1289. doi: 10.4319/lo.2004.49.4_part_2.1278

Li, K., Bai, Z., and Zhang, H. (2015). Community succession of bacteria and eukaryotes in dune ecosystems of Gurbantunggut Desert, Northwest China. Extremophiles 19, 171-181. doi: 10.1007/s00792-014-0696-Z

Liu, R., Li, K., Zhang, H., Zhu, J., and Joshi, D. (2014). Spatial distribution of microbial communities associated with dune landform in the Gurbantunggut Desert, China. J. Microbiol. 52, 898-907. doi: 10.1007/s12275-0144075-3

Livingstone, I. (2013). Aeolian geomorphology of the Namib Sand Sea. J. Arid Environ. 93, 30-39. doi: 10.1016/j.jaridenv.2012.08.005

Makhalanyane, T. P., Valverde, A., Gunnigle, E., Frossard, A., Ramond, J.-B., and Cowan, D. A. (2015). Microbial ecology of hot desert edaphic systems. FEMS Microbiol. Rev. 39, 203-221. doi: 10.1093/femsre/fuu011

Nelson, R. (1982). "Carbonate and gypsum," in Methods of Soil Analysis Part 2 Chemical and Microbiological Properties, ed A. G. Norman (Madison, WI: American Society of Agronomy), 181-197.
Oksanen, J. (2013). Multivariate Analysis of Ecological Communities in R: Vegan Tutorial. Available online at: http://cc.oulu.fi/ jarioksa/opetus/metodi/ vegantutor.pdf

Olsen, S. R., Cole, C. V., Watanabe, F. S., and Dean, L. A. (1954). Estimation of Available Phosphorus in Soils by Extraction with Sodium Bicarbonate. USDA Circular 939. Washington, DC: Government Printing Office.

Prosser, J. I. (2010). Replicate or lie. Environ. Microbiol. 12, 1806-1810. doi: $10.1111 / j .1462-2920.2010 .02201 . x$

Quince, C., Lanzen, A., Davenport, R. J., and Turnbaugh, P. J. (2011). Removing noise from pyrosequenced amplicons. BMC Bioinformatics 12:38. doi: 10.1186/1471-2105-12-38

Ramond, J.-B., Pienaar, A., Armstrong, A., Seely, M., and Cowan, D. A. (2014). Niche-partitioning of edaphic microbial communities in the Namib Desert gravel plain Fairy Circles. PLoS ONE 9:e109539. doi: 10.1371/journal.pone.0109539

Ramond, J.-B., Welz, P. J., Cowan, D. A., and Burton, S. G. (2012). Microbial community structure stability, a key parameter in monitoring the development of constructed wetland mesocosms during start-up. Res. Microbiol. 163, 28-35. doi: 10.1016/j.resmic.2011.09.003

Reysenbach, A. L., and Pace, N. R. (1995). Archaea: A Laboratory ManualThermophiles. New York, NY: Cold Spring Harbour Laboratory Press.

Rhoades, J. D. (1982). "Cation exchange capacity," in Methods of Soil Analysis Part 2. Chemical and Microbiological Properties, ed A. G. Norman (Madison, WI: American Society of Agronomy), 149-157.

Schloss, P. D., Westcott, S. L., Ryabin, T., Hall, J. R., Hartmann, M., Hollister, E. B., et al. (2009). Introducing mothur: open-source, platformindependent, community-Supported software for describing and comparing microbial communities. Appl. Environ. Microbiol. 75, 7537-7541. doi: 10.1128/AEM.01541-09

Seely, M. (2012). Namib Sand Sea World Heritage Nomination. Windhoek: UNESCO Namibian National Committee for World Heritage.

Seely, M., and Pallett, J. (2008). Namib: Secrets of a Desert Uncovered. Windhoek: Venture Publications.

Seely, M. K. (1990). Patterns of plant establishment on a linear desert dune. Israel J. Bot. 39, 443-451.

Sharma, R., Manda, R., Gupta, S., Kumar, S., and Kumar, V. (2013). Isolation and characterization of osmotolerant bacteria from Thar desert of western Rajasthan (India). Rev. Biol. Trop. 61, 1551-1562. doi: 10.15517/rbt.v61i4.12790

Stomeo, F., Valverde, A., Pointing, S. B., McKay, C. P., Warren-Rhodes, K. A., Tuffin, M. I., et al. (2013). Hypolithic and soil microbial community assembly along an aridity gradient in the Namib Desert. Extremophiles 17, 329-337. doi: 10.1007/s00792-013-0519-7

Thomas, A. D., and Dougill, A. J. (2007). Spatial and temporal distribution of cyanobacterial soil crusts in the Kalahari: implications for soil surface properties. Geomorphology 85, 17-29. doi: 10.1016/j.geomorph.2006.03.029

Vellend, M. (2010). Conceptual synthesis in community ecology. Q. Rev. Biol. 85, 183-206. doi: 10.1086/652373

Walden, J., and White, K. (1997). Investigation of the controls on dune colour in the Namib Sand Sea using mineral magnetic analyses. Earth Planet. Sci. Lett. 152, 187-201. doi: 10.1016/S0012-821X(97)00154-4

Walkley, A. (1935). An examination of methods for determining organic carbon and nitrogen in soils. J. Agric. Sci. 25, 598-609. doi: 10.1017/S0021859600019687

Warren-Rhodes, K. A., McKay, C. P., Boyle, L. N., Wing, M. R., Kiekebusch, E. M., Cowan, D. A., et al. (2013). Physical ecology of hypolithic communities in the central Namib Desert: the role of fog, rain, rock habitat, and light. J. Geophys. Res. 118, 1451-1460. doi: 10.1002/jgrg.20117

Welz, P. J., Ramond, J.-B., Cowan, D. A., Burton, S. G., and Le Roes-Hill, M. (2014). Minor differences in sand physicochemistry lead to major differences in bacterial community structure and function after exposure to synthetic acid mine drainage. Biotechnol. Bioprocess Eng. 19, 211-220. doi: 10.1007/s12257013-0454-6

Yamaguchi, N., Ichijo, T., Sakotani, A., Baba, T., and Nasu, M. (2012). Global dispersion of bacterial cells on Asian dust. Sci. Rep. 2:525. doi: $10.1038 /$ srep00525

Yeaton, R. I. (1988). Structure and function of the Namib dune grasslands: characteristics of the environmental gradients and species distributions. J. Ecol. 76, 744. doi: $10.2307 / 2260571$ 
Yu, J., and Steinberger, Y. (2012a). Soil microbial metabolic profiles in two geomorphological units in a semistable sand-dune ecosystem. Soil Biol. Biochem. 45, 71-78. doi: 10.1016/j.soilbio.2011.10.005

Yu, J., and Steinberger, Y. (2012b). Spatiotemporal changes in abiotic properties, microbial $\mathrm{CO}_{2}$ evolution, and biomass in playa and crust-covered interdune soils in a sand-dune desert ecosystem. Eur. J. Soil Biol. 50, 7-14. doi: 10.1016/j.ejsobi.2011.11.007

Zhang, P., Zheng, J., Pan, G., Zhang, X., Li, L., and Rolf, T. (2007). Changes in microbial community structure and function within particle size fractions of a paddy soil under different long-term fertilization treatments from the Tai Lake region China. Colloids Surf. B. 58, 264-270. doi: 10.1016/j.colsurfb.2007.03.018
Conflict of Interest Statement: The authors declare that the research was conducted in the absence of any commercial or financial relationships that could be construed as a potential conflict of interest.

Copyright (๑) 2015 Ronca, Ramond, Jones, Seely and Cowan. This is an openaccess article distributed under the terms of the Creative Commons Attribution License (CC BY). The use, distribution or reproduction in other forums is permitted, provided the original author(s) or licensor are credited and that the original publication in this journal is cited, in accordance with accepted academic practice. No use, distribution or reproduction is permitted which does not comply with these terms. 